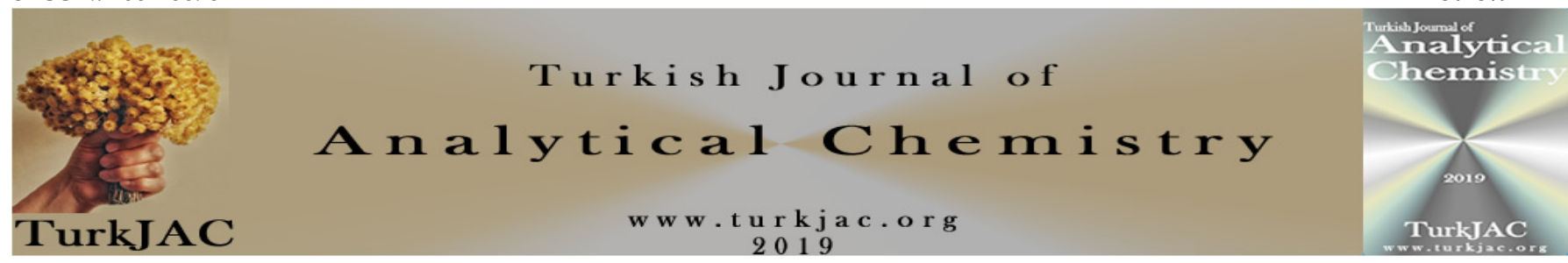

\title{
The recent studies about the interaction of phthalocyanines with DNA
}

\author{
Esra Bağda ${ }^{1 *}$ iD, Efkan Bağda² iD \\ 1Sivas Cumhuriyet University, Faculty of Pharmacy, Department of Basic Pharmaceutical Sciences, Analytical Chemistry Division, 58140, Sivas, \\ Turkey \\ ${ }^{2}$ Sivas Cumhuriyet University, Faculty of Science, Department of Molecular Biology and Genetics, 58140, Sivas, Turkey
}

\begin{abstract}
Cancer is one of the major diseases affecting all humanity with high mortality rates worldwide. Photodynamic therapy offers one of the most important and promising treatment methods, especially in recent years. Photodynamic therapy takes the steps of administering the photosensitizing compound to the body and stimulating it with a light of an appropriate wavelength after its accumulation in the target tissue. With the formation of complex processes that take place in the target area with the reactive oxygen species formed by the stimulated compounds, death or the inhibition of the proliferation of the cells causes situations such as the destruction of the target tissue.

Phthalocyanines constitute an important group of photo-sensitizers with their strong absorption close to the therapeutic window. With large $\Pi$ systems, they can bind with many biological macromolecules with high affinity by many mechanisms, including the $\Pi$ - $\Pi$ stacking.

This review article describes the last three years of studies in the WOS (Web of Science) database about the interactions of phthalocyanines with DNA. The interactions of phthalocyanines with DNA are important as they can make differences in the proliferation of tumour cells. On the other hand, DNA replication and transcription have increased due to the increased metabolic rate of these cells. The DNA double-strand opened during replication, and gene expression allows the formation of different secondary structures such as hairpin, triple and G-quadruplex. The interaction of G-quadruplex DNA structures with these compounds, which can be formed in the guanine-rich regions of the DNA has been described in studies.
\end{abstract}

Keywords: G-quadruplex, DNA, phthalocyanine, interaction

\section{Introduction}

Phthalocyanines are synthetic dyes and composed of four benzoid nuclei joined by four nitrogen atoms [1, 2]. These compounds have very important advantages such as definite chemical structure, repeatable synthesis, strong absorption in the near-infrared region, tunable photophysical and photochemical properties, and inherent biodegradability [3]. The free and metallated phthalocyanines have characteristic bands on the ultraviolet-visible absorption spectrum: a broad Soret band at 300-425 $\mathrm{nm}$ and $Q$ band at 550-750 nm [4] .

Apart from usage as photosensitizers for photodynamic therapy, phthalocyanines have been used in the different technological fields such as solar cell materials $[5,6,7,8]$, non-linear optical materials $[9,10$, 11].

Genome integrity is essential for proper cell proliferation. Genetic instability can result in the inhibition of proliferation and some diseases [12]. Deoxyribonucleic acid (DNA) is a very important biopolymer that acts as a target for a large number of drugs, therefore, investigation of interactions of DNA with small molecules which are potential drugs is important for designing new types of pharmaceuticals [13]. The investigation of the interaction of drugs with DNA is a very important task in pharmacology as DNA is often the target for the majority of anticancer and antibiotic drugs [14].

G-quadruplexes DNA (G-Q) are four-stranded secondary DNA structures forming in guanine-rich nucleic acids regions of the genome, which can be found in some important parts of the genome such as promoter regions [15]. G-Q structures stabilized by Hoogsteen hydrogen bonding between a tetrad of guanine bases [16]. The G-quadruplex structure has essential roles in many biological processes such as translation, telomere maintenance, transcription, and replication [17, 18, 19]. According to De Magis et al., G-quadruplexes DNA and $\mathrm{R}$ loops are non-canonical DNA structures, and they can
Citation: E. Bağda, E. Bağda, The recent studies about the interaction of phthalocyanine with DNA, Turk J Anal Chem, 3(1), 2021, 9-18.

\author{
*Author of correspondence: esraer@cumhuriyet.edu.tr \\ Tel: +90 3462191010 \\ Fax +90346 2191634 \\ Received: May 18, 2021 \\ Accepted: June 13, 2021


regulate basic nuclear processes and trigger DNA damage, genome instability, and cell killing [20].

The important roles of DNA and G-quadruplex DNA structures in the cell cycle have made these structures targets for cancer drugs. Molecules that bind effectively to DNA structures can alter the normal process of the cell. This situation is very promising for cancer treatment.

In this review, phthalocyanines, molecules that can bind with B-DNA and G-quadruplex DNA, were investigated.

When searching WOS with "phthalocyanine" and "DNA" keywords (topic), 528 studies were found (Access date to WOS 12.05.2021). According to the WOS categories, out of 528 studies, 128 belongs to the "chemistry multidisciplinary" category, 123 belongs to the "biochemistry, molecular biology" category, 60 belongs to the "biophysics" category, 51 belongs to the "chemistry physical" category, 39 belongs to "chemistry inorganic nuclear" category, 36 belongs to "chemistry analytical" category, 31 belongs to "oncology" category.
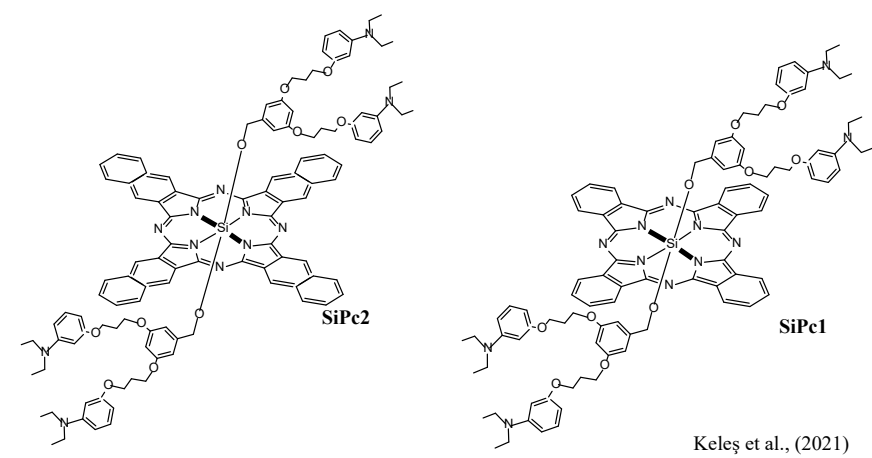

Figure 1. The structure of silicon phthalocyanines used in the study of Keleş et al. [21]

When the studies are evaluated according to the years they were published, there are most studies in 2020 (42), 37 in 2018, 30 in 2019, 29 in 2017, and 28 in 2016.

According to document types, 475 documents are articles, 30 documents are proceeding papers and 30 reviews.

When the studies grouped into funding agencies, 64 of them funded by the National Natural Science Foundation of China (NSFC), 45 of them funded by the United States Department Of Health Human Services, 44 of them funded by the National Institutes of Health (NIH) USA, 33 of them funded by (NIH) National Cancer Institute (NCI), 24 of them funded by Grants in Aid for Scientific Research Kakenhi, 24 of them funded by Japan Society for the Promotion of Science, 24 of them funded by Ministry of Education Culture Sports Science and Technology Japan (MEXT), 23 of them funded by The Scientific and Technological Research Council of Turkey (TUBITAK), 18 of them funded by European
Commission, 14 of them funded by Conselho Nacional De Desenvolvimento Cientifico E Tecnologico (CNPQ).

When the studies are evaluated according to "organization-enhanced", 30 documents from Karadeniz Technical University, 24 from Case Western Reserve University, 22 from Chinese Academy Of Sciences, 15 from Istanbul Technical University, 15 from Russian Academy of Sciences, 15 from Universidade De Sao Paulo, 12 from Gebze Technical University, 12 from Centre National De La Recherche Scientifique CNRS, 10 from Institute of Chemical Biology Fundamental Medicine Siberian Branch of The Ras, and 10 from University of Sherbrooke.

\section{Literature Survey}

The studies obtained from the research in WOS and belonging to the last three years can be briefly summarized as follows.

Keleş et al., have synthesized and characterized the water-soluble and non-aggregated silicon (IV) phthalocyanines and naphthalocyanines containing (3,5-bis\{3-[3(diethylamino)phenoxy]propoxy\}phenyl)methoxy groups to investigate their anticancer potential (Fig. 1) [21]. They conducted the experiments to investigate the ct-DNA interaction of the compounds and the binding constant $\left(\mathrm{K}_{\mathrm{b}}\right)$ values of SiPc1a and SiNc2a were found as $6.85 \pm(0.35) \times 10^{6}$ and $1.72 \pm(0.16) \times 10^{4} \mathrm{M}^{-1}$. It is also reported that the $\Delta \mathrm{T}_{\mathrm{m}}$ values of SiPc1a and SiNc2a were calculated as 6.45 and $2.50{ }^{\circ} \mathrm{C}$, respectively. They concluded from the all obtained experimental results that SiPc1a is a promising candidate as an anticancer agent [21].
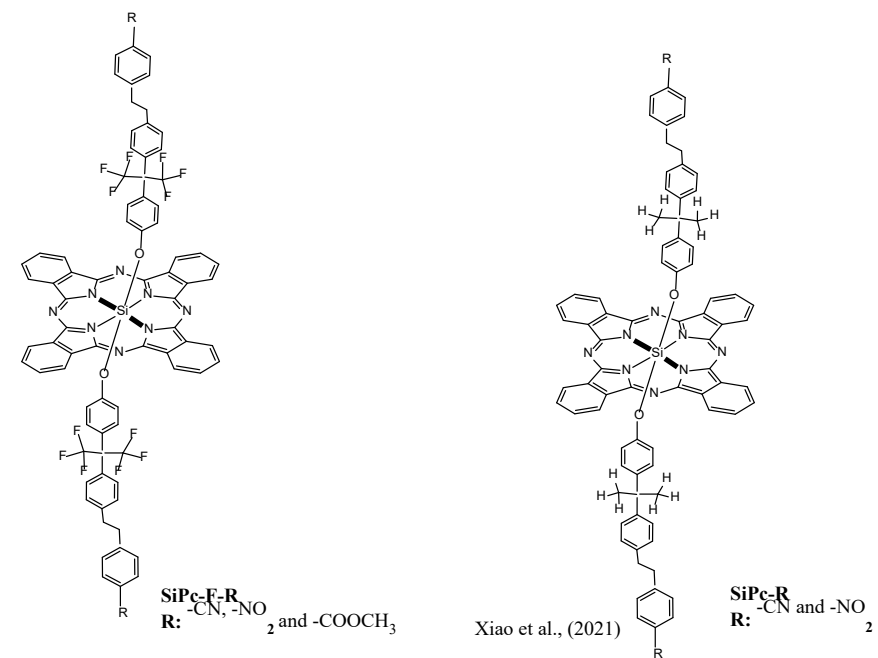

Figure 2. The structure of silicon phthalocyanines used in the study of Xiao et al. [22]

Xiao et al., have synthesized and characterized two series of fluorinated and non-fluorinated dendritic silicon (IV) phthalocyanines with cyano/nitro/ester terminal functionalities (Fig. 2) [22]. They used an 
amphiphilic diblock copolymer polyethylene glycol monomethyl ether-polycaprolactone to encapsulate these silicon phthalocyanines to form fluorinated and non-fluorinated dendritic silicon phthalocyanines nanoparticles to endow water-soluble and biocompatibility of the compounds. The binding constants $\left(\mathrm{K}_{\mathrm{a}}\right)$ between the fluorinated dendritic silicon nanoparticles and DNA were $3.569 \times 10^{3}$ for MPEG@SiPc-F-CN, $3.887 \times 10^{3}$ for MPEG@SiPc-F-NO2, and $4.629 \times 10^{3} \mathrm{M}^{-1}$ for MPEG@SiPc-F-COOCH . to support the binding experiments results in the competition binding sites experiment was also conducted by Xiao et al., and they concluded that the interaction between the DNA with nanoparticles could be explained that the interaction between "positive charge" of fluorinated dendritic silicon phthalocyanines and the negative phosphate backbone of DNA [22].
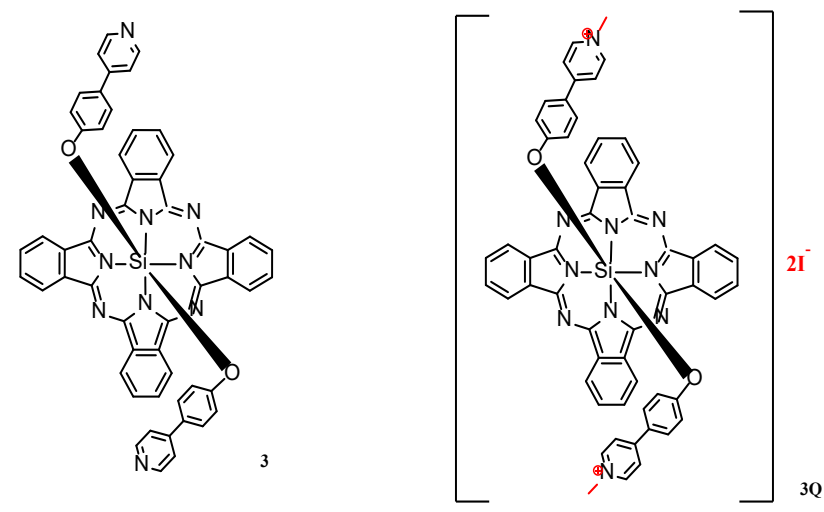

Figure 3. The structure of silicon phthalocyanine used in the study of Al-Raqa et al. [23]

Al-Raqa et al., synthesized and characterized axially the novel bis[4-(4-pyridinyl)phenol] substituted silicon(IV) phthalocyanine (3) and its quaternized derivative (3Q) (Fig. 3) [23]. The binding constants $(\mathrm{Kb})$ between the quaternized derivative (3Q) and ct-DNA was $3.09 \times 10^{6} \mathrm{M}^{-1}$, the binding stoichiometry $(\mathrm{n})$ was found as 1.57. They stated that the presence of an isosbestic point at $703 \mathrm{~nm}$ supports the intercalation mode of interaction between $3 \mathbf{Q}$ and ct-DNA [23].

A study conducted by our research group was about the interaction of a water-soluble quaternized nonperipherally gallium(III)phthalocyanine chloride $(\mathrm{GaPc})$ bearing 2-mercapto- $\mathrm{N}$-methylpyridinium groups with different G- quadruplex DNA and ct-DNA. We found that the GaPc complex has a higher affinity to Gquadruplex DNA structures [24]. The binding constants were found as $1.9 \times 10^{6} \mathrm{M}^{-1}, 1.1 \times 10^{6} \mathrm{M}^{-1}, 8.5 \times 10^{5} \mathrm{M}^{-1}$ for c-MYC, AS1411, Tel21, and it was found as $2.9 \times 10^{4}$ $\mathrm{M}^{-1}$ for ct-DNA.

Uchiyama et al., studied the interaction between an all parallel-stranded tetrameric G-quadruplex formed from a heptanucleotide d(TTAGGGT) ([d(TTAGGGT)]4) and $\mathrm{Ga}(\mathrm{III})$ phthalocyanine $(\mathrm{Pc})$ derivative bearing eight
$\mathrm{N}$-methylpyridinium groups at peripheral $\beta$-positions $(2,3,6,7,10,11,14,15$-octakis-[N-methyl-(4-

methylpyridinium-3-yloxy) phthalocyaninato] chloro gallium(III) iodide (GaPc)) (Fig. 4) [25]. They stated that GaPc exhibits stepwise binding to the G-quadruplex DNA to form a 2:1 GaPc-DNA complex. The binding constans for the first and second steps were found as $(21 \pm 2) \times 10^{6}$ and $(0.09 \pm 0.06) \times 10^{6} \mathrm{M}^{-1}$. They found that GaPc exhibits high binding affinity to the A3G4 step of [d(TTAGGGT)] 4 through the electrostatic interactions of its positively-charged side chains with the negativelycharged phosphate groups, in addition to the $\pi-\pi$ stacking interaction. They concluded that the polarity of the binding site alters the GaPc-binding affinity to the DNA [25].

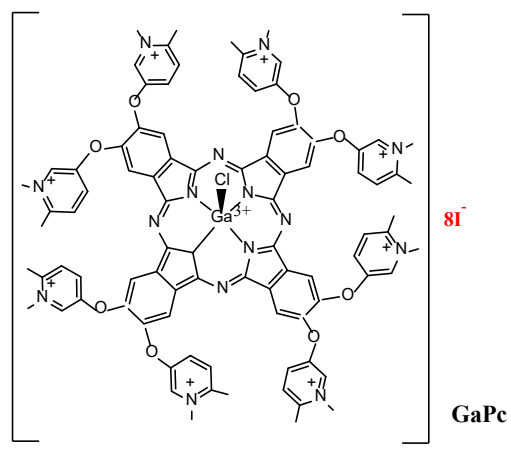

Figure 4. The structure of Ga(III) phthalocyanine used in the study of Uchiyama et al. [25]

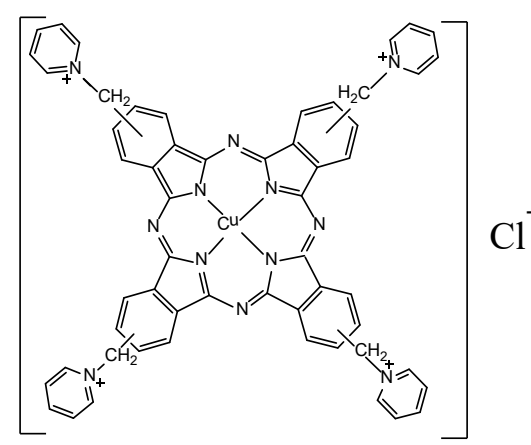

Figure 5. The structure of $\mathrm{Cu}(\mathrm{II})$ phthalocyanine used in the study of Macii et al. [26]

Macii et al., investigated the binding mechanism of a is a well know dye, copper phthalocyanine (Alcian Bluetetrakis(methylpyridinium) chloride, ABTP) (Fig. 5), to natural ct-DNA, G-quadruplexes (G4), and synthetic RNA polynucleotides in the form of double polyriboadenylic.polyribouridylic acid $(\operatorname{poly}(\mathrm{A}) \cdot \operatorname{poly}(\mathrm{U}))$ or triple strands polyriboadenylic.2polyribouridylic acid (poly(A).2poly(U)). Kapp is the binding constant and in the presence of $\mathrm{NaCl} 0.1 \mathrm{M}, \mathrm{NaCa} 2.5 \mathrm{mM}, \mathrm{pH} 7.0$ and 25 ${ }^{\circ} \mathrm{C}$ they calculated the values as $\quad \mathrm{K}_{\text {app }}(\mathrm{ABTP} / \mathrm{ct}$ DNA $)=(5.0 \pm 1.1) \times 10^{3} \mathrm{M}^{-1}, \mathrm{~K}_{\text {app }}(\mathrm{ABTP} /$ polyA $\cdot$ polyU $)=$ $(1.2 \pm 0.6) \times 10^{4} \mathrm{M}^{-1}$ and $\mathrm{Kapp}(\mathrm{ABTP} /$ polyA $\cdot 2$ polyU $)=(6.2$ $\pm 3.2) \times 10^{3} \mathrm{M}^{-1}$ [26]. They also conducted the titrations experiments in the range of $15-46^{\circ} \mathrm{C}$ and calculated the 
thermodynamic parameters. They stated that magnitude for enthalpy changes lies at the boundaries between groove binding (low negative or positive $\Delta \mathrm{H}$ ) and intercalation (highly negative $\Delta \mathrm{H}$ ). They also conducted melting studies and concluded that the significant helix stabilization observed upon ABTP binding (at CABTP/Cpoly $=1.25, \Delta \mathrm{Tm}>15{ }^{\circ} \mathrm{C}$ for both ABTP/polyA.polyU and ABTP/polyA-2polyU. They also conducted similar experiments with Gquadruplexes and the apparent binding constants were calculated as Kapp $(\mathbf{A B T P} /$ Tel23 $)=(3.7 \pm 1.2) \times 10^{5} \mathrm{M}^{-1}$, $\mathrm{K}_{\text {app }}(\mathrm{ABTP} / \mathrm{c}-\mathrm{myc})=(3.6 \pm 1.1) \times 10^{5} \mathrm{M}^{-1}$ and $\mathrm{K}_{\text {app }}$ $($ ABTP/CTA22 $)=(6.1 \pm 2.1) \times 10^{5} \mathrm{M}^{-1}(\mathrm{KCl} 0.1 \mathrm{M}, \mathrm{LiCaC}$ $2.5 \mathrm{mM}, \mathrm{pH} 7.0,25.0^{\circ} \mathrm{C}$ ). They concluded from the thermodynamic studies that the low values of $\Delta \mathrm{H}_{\text {app }}$ agree with externally binding. Interestingly, the $C D$ experiments strongly indicate dye intercalation in the case of ABTP with ct-DNA [26].

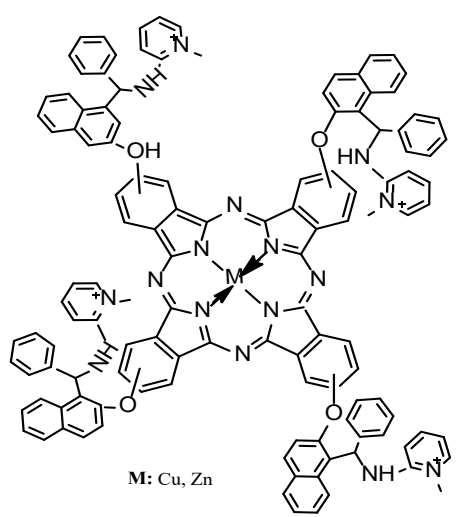

Figure 6. The structure of phthalocyanines used in the study of Amitha and Vasudevan [27]

Amitha and Vasudevan synthesized Betti base substituted zinc and copper phthalocyanines (ZnBBPc and $\mathrm{CuBBPc}$ ) and their quaternized derivatives qZnBBPc and qCuBBPc were and characterized (Fig. 6) [27]. The DNA binding activities of qZnBBPc and qCuBBPc against ct-DNA were investigated and intercalative mode of interaction with $\mathrm{K}_{\mathrm{b}}$ of the order of $10^{5} \mathrm{M}^{-1}$ was found. They finally assumed that the preferred mode of interaction was intercalative and the activity followed the order qCuBBPc $>$ qZnBBPc [27].

Çoban et al., investigated some biological applications such as ct-DNA binding and supercoiled plasmid pBR322 DNA cleavage of zinc (II) phthalocyanine bearing ferrocene groups (Pc-Zn) [28]. They calculated the binding constant $\left(\mathrm{K}_{\mathrm{b}}\right)$ value of the Pc$\mathrm{Zn}$ as $1.80 \pm(0.37) \times 10^{4} \mathrm{M}^{-1}$ and hypochromicity \% as $29.71 \pm 3.45$. They concluded the binding mechanism as groove binding because the binding constant of $\mathbf{P c}-\mathbf{Z n}$ found lower than $10^{5}-10^{9} \mathrm{M}^{-1}$ which are the $\mathrm{K}_{\mathrm{b}}$ values of intercalation [28].

Barut et al., synthesized the peripherally and nonperipherally tetra substituted water-soluble zinc(II) phthalocyanines ( $\mathbf{5} \mathbf{a}$ and $\mathbf{5 b}$ ), and their ct-DNA binding behavior was investigated as well as other biological applications (Fig. 7) [29]. The binding constants were found to be $2.92 \pm(0.20) \times 10^{5}$ and $1.30 \pm(0.16) \times 10^{6} \mathrm{M}^{-1}$ for $5 \mathbf{a}$ and $5 \mathbf{b}$. They concluded that compound $\mathbf{5 b}$ interacted with DNA 10 times stronger than $\mathbf{5 a}$.
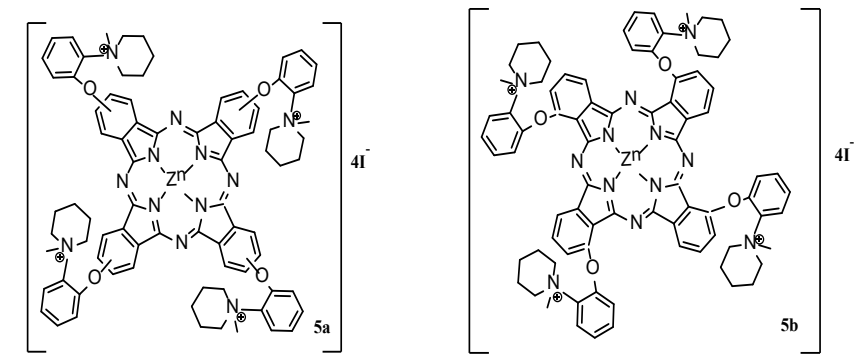

Figure 7. The structure of $\mathrm{Zn}$ (II) phthalocyanines used in the study of Barut et al. [29]

Khezami et al., synthesized two new tetra- or octasubstituted zinc(II) phthalocyanines (1 and $\mathbf{2}$ ) bearing 3(morpholinomethyl)phenyl groups [30]. They also converted $\mathbf{1}$ and $\mathbf{2}$ to their water-soluble derivatives (1Q and $2 Q$ ) by quaternization. They investigated the interaction of $1 \mathbf{Q}$ and $2 \mathrm{Q}$ with ct-DNA as well as BSA. They found the $\mathrm{Kb}$ values as $6.3 \times 10^{4}$ and $1.5 \times 10^{5} \mathrm{M}^{-1}$.
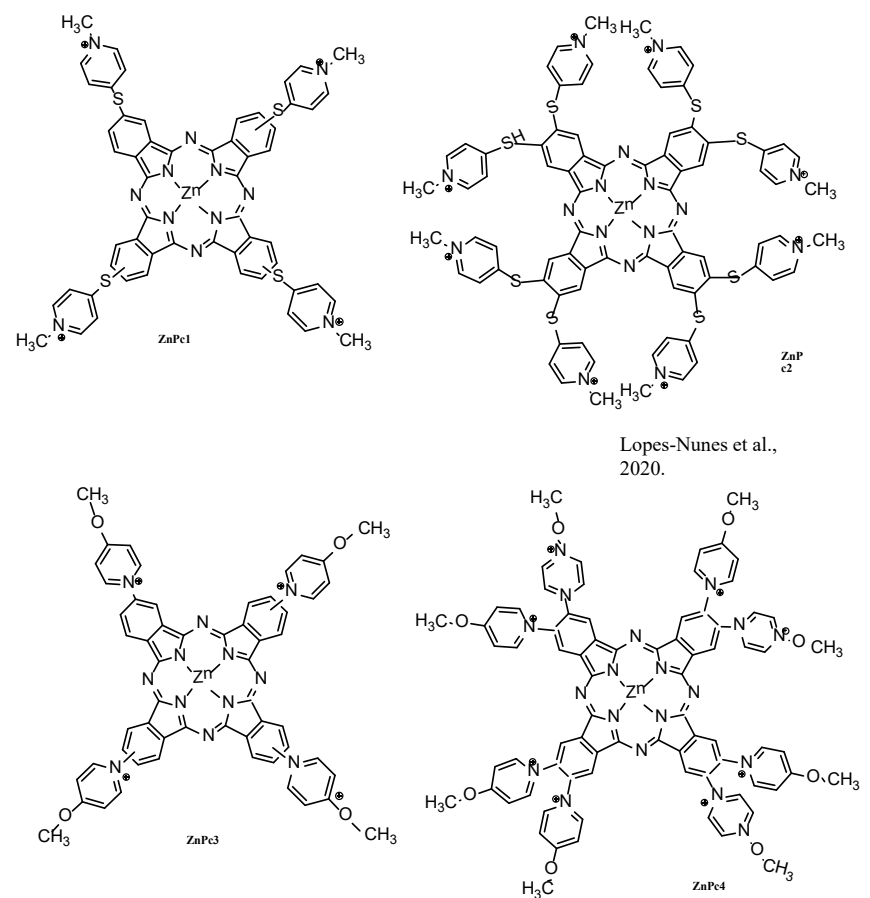

Figure 8. The structure of $\mathrm{Zn}$ (II) phthalocyanines used in the study of Lopes-Nunes et al. [31]

Lopes-Nunes et al., studied the interactions of four Zn(II) phthalocyanines (thiopyridinium ZnPcs 1 and 2, and methoxypyridinium ZnPcs 3 and 4) (Fig. 8) with the G-quadruplex forming AS1411 aptamer and its derived sequences AT11, -L0 and -B0 [31]. They calculated the dissociation constants and concluded that $\mathrm{ZnPc} 4$ has the highest affinity for all G4s aptamers; this is due to a compromise between the eight positive charges and 
their hindered location in the methoxypyridinium moieties.

Ball et al., reported the ct-DNA binding properties of tetra phenoxy-3-methoxybenzoic acid substituted Co(II) (4) and $\mathrm{Cu}$ (II) (5) metal phthalocyanines (Fig. 9) [32]. They found the binding constants as $1.85 \times 10^{6}$ and $2.22 \times 10^{6}$. They assumed that both two phthalocyanine compounds bound to the ct-DNA using the intercalation binding mechanism. Ball et al, found the Tm value of bare calf thymus DNA as $74.63^{\circ} \mathrm{C}$ and $79.48^{\circ} \mathrm{C}$ and 80.75 ${ }^{\circ} \mathrm{C}$. They suggested that the melting temperature also demonstrated intercalation binding mechanism for the compound 4 and 5 [32].

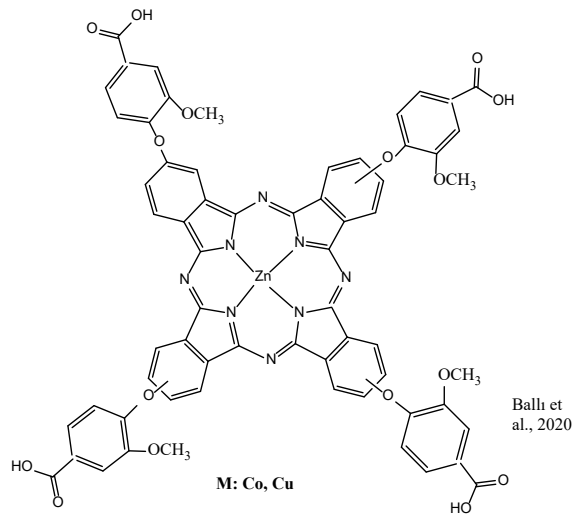

Figure 9. The structure of phthalocyanines used in the study of Balli et al. [32]

Uchiyama et al., investigated the G-quadruplex DNA binding behavior of 2,9(10),16(17),23(24)tetrakis(carboxyl)phthalocyanine copper(II) complex (CuTCPc) (Fig. 10) [33]. The compound, CuTCPc, is an anionic phthalocyanine and the researchers found that binds this anionic phthalocyanine compound selectively to the 3'-terminal G-quartet, i.e., G6 G-quartet, of the all parallel-stranded tetrameric G-quadruplex of $\mathrm{d}$ (TTAGGG). The addition of an extra T at the 3 '-terminal of the constituent sequence inhibited the specific binding of $\mathrm{CuTCPc}$ to G6 G-quartet. They concluded that the inhibition of specific binding is most likely due to the electrostatic repulsion between the carboxylate groups of CuTCPc and the negatively-charged phosphate of the phosphodiester bond at the G6T7 step of the Gquadruplex DNA [33].

Yalazan et al., synthesized tosylated 4morpholinoaniline units fused peripherally tetrasubstituted free-base (5), copper(II) (6), zinc(II) (7), cobalt(II) (8), and magnesium(II) (9) (Fig. 11) phthalocyanine compounds [34]. The DNA interaction of 7 was investigated and the intrinsic binding constant was determined as $2.45 \pm(0.20) \times 10^{4} \mathrm{M}^{-1}$. $25.98 \%$ of hypochromic effect was observed for compound 7 without any shift upon the addition of ct-DNA. The authors concluded from the results that compound (7) bound to ct-DNA via non-covalent interaction [34].

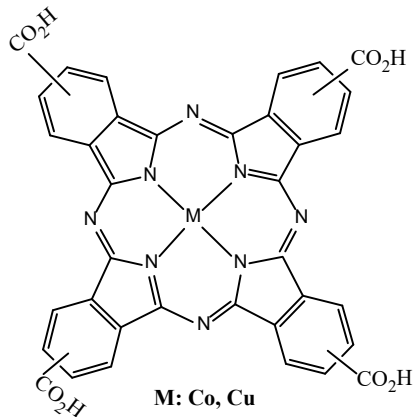

Figure 10. The structure of phthalocyanines used in the study of Uchiyama et al. [33]

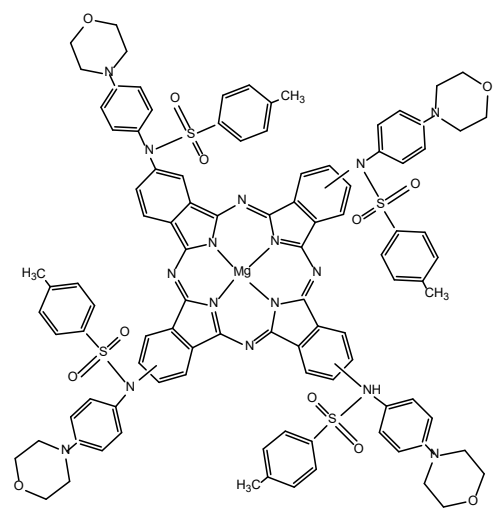

Figure 11. The structure of $\mathrm{Mg}(\mathrm{II})$ phthalocyanine used in the study of Yalazan et al. [34]

Yan et al., investigated the photodynamic therapy with a zinc phthalocyanine (ZnPc) photosensitizer coupled with 2,4,6-tris (N, N-dimethylaminomethyl) phenoxy (TAP), termed as $\mathbf{Z n P c}(\mathrm{TAP})_{4}$ (Fig. 12) [35]. They investigated the ct-DNA binding and they found the $\mathrm{K}_{\mathrm{b}}$, intrinsic binding constant as $3.2 \times 10^{6}$. They commented that the intrinsic binding constant for $\mathrm{ZnPc}$ (TAP)4 is higher than that of ethidium bromide $\left(\mathrm{K}_{\mathrm{b}}=1.23 \times 10^{5}\right)$ showing that $\mathrm{ZnPc}(\mathrm{TAP}) 4$ has a strong affinity to ct-DNA.

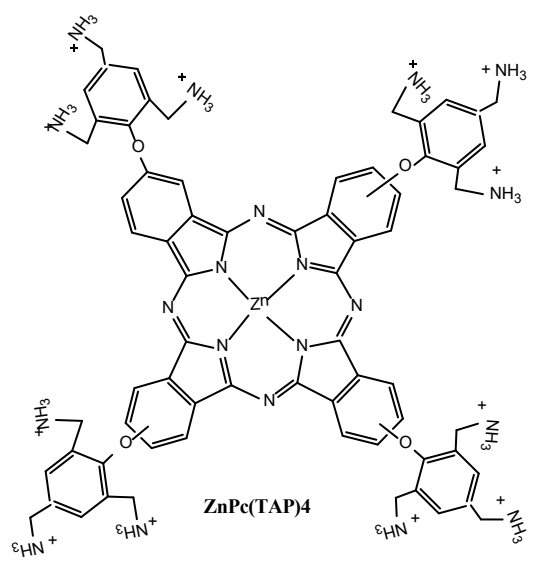

Figure 12. The structure of $\mathrm{Zn}(\mathrm{II})$ phthalocyanine used in the study of Yan et al. [35]

Wang et al., studied the specific binding of the anionic phthalocyanine $3,4^{\prime}, 4^{\prime \prime}, 4^{\prime \prime \prime}$-tetrasulfonic acid 
(APC) (Fig. 13) to the human hybrid (3+1) G4s [36]. They investigated the binding at the atomic level using molecular docking and molecular dynamics simulations. They suggested that APC preferred the end-stacking binding with the telomere hybrid type II G4 and the groove binding with the hybrid type I G4. They also commented that the electrostatic interaction and the polar solvation effect made unfavorable and favorable contributions respectively to the binding of APC and hybrid G4s [36].

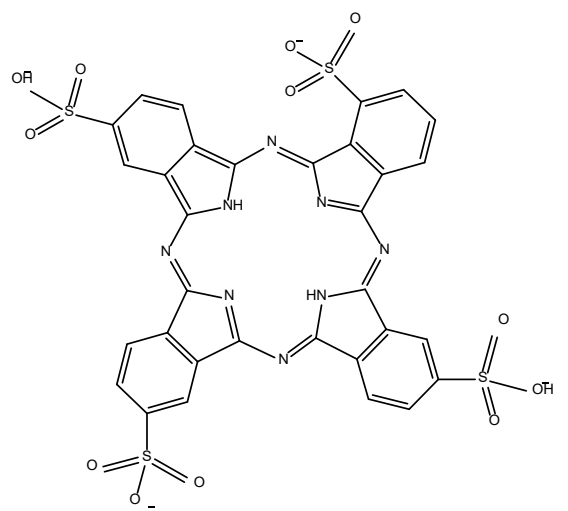

Figure 13. The structure of phthalocyanine used in the study of Wang et al. [36]

A tetra substituted neutral zinc phthalocyanine (ZnPc-4) (Fig. 14) bearing 4-phenylazophenoxy group at the periphery had been prepared by [37]. The interaction between ct-DNA and ZnPc-4 was investigated. They concluded from the electronic spectrum results as well as the planar shape of the compound that intercalation mode of binding with ct-DNA. They calculated the binding constant as $1.58 \times 10^{5} \mathrm{M}^{-1}$.

Baran et al., synthesized three phthalocyanine derivatives ( $\mathrm{Zn} \mathrm{(3a),} \mathrm{Co} \mathrm{(3b),} \mathrm{and} \mathrm{metal-free} \mathrm{(3c))} \mathrm{were}$ synthesized (Fig. 15) [38]. The ct-DNA binding studies conducted with $3 \mathbf{a}$. the binding constant of $3 \mathbf{a}$ calculated as $5.2( \pm 0.52) 10^{3} \mathrm{M}^{-1}$. They concluded from the spectral data that the existence of non-intercalative interactions between the synthesized Pcs and ct-DNA.

Kasyanenko et al., investigated the ct-DNA interaction of cobalt phthalocyanine disodium disulfonate (CoPc) (Fig. 16) [39]. The authors claimed that two types of CoPc binding to DNA were observed. For the first binding, fast CoPc interactions with DNA via external binding to DNA phosphates backbone were accompanied by the formation of stack-type phthalocyanine structures on the periphery of the DNA helix (binding constant was found as $(4.8 \pm 0.4) \times 10^{4} \mathrm{M}^{-1}$. The authors stated that the second binding manifests itself in a certain period of time. It can be associated with the reorganization of ligands and second binding does not affect the first complexes, that is CoPc binding with DNA phosphates [39].

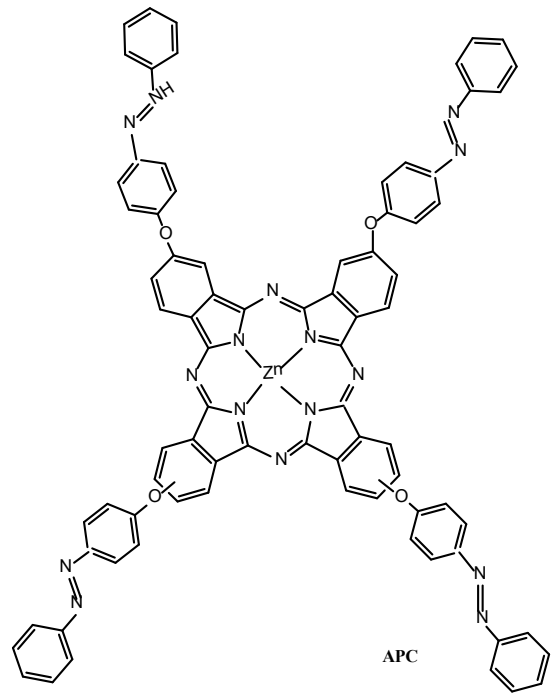

Figure 14. The structure of $\mathrm{Zn}(\mathrm{II})$ phthalocyanine used in the study of Amita and Vasudevan [37]

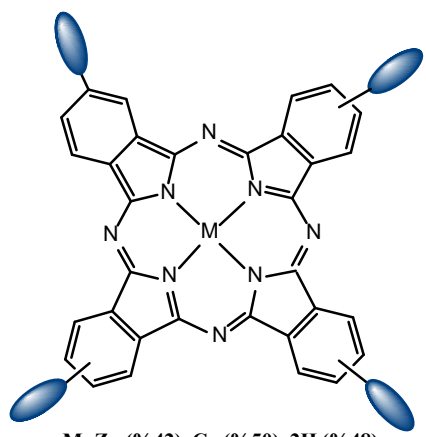

M: Zn (\%42), Co (\%50), $2 \mathrm{H}(\% 48)$

Figure 15. The structure of phthalocyanines used in the study of Baran et al. [38]

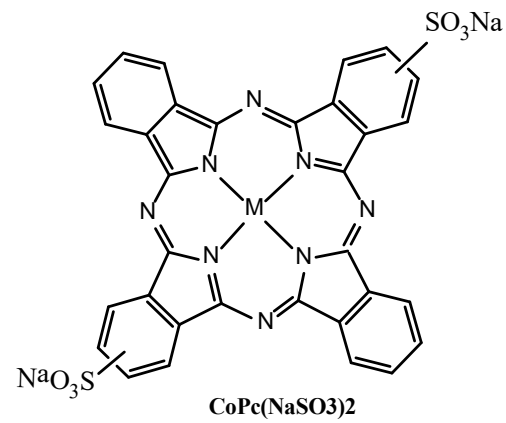

Figure 16. The structure of phthalocyanine used in the study of Kasyanenko et al. [39]

McRae et al., have studied the interaction of two cationic zinc phthalocyanines (Pc1 and Pc2) with several DNA secondary structures (ss-DNA, ds-DNA, and G4DNA structures) [40]. They suggested that according to the spectrophotometric titration experiment there are strong interactions between both phthalocyanine compounds and ss-DNA, ds-DNA, and G4-DNA and consistent with non-specific interactions with the phosphodiester backbone.

Keleş et al., have synthesized axially [3,5-bis(3pyridin-4-ylpropoxy)phenyl]methoxy groups substituted silicon (IV) phthalocyanine 2, 
napthalocyanine 3 and their water-soluble derivatives 2a, 3a (Fig. 17) [41]. They found that the $\mathbf{3 a}$ and $\mathbf{3} \mathbf{b}$ interacted to ct-DNA via intercalation with a binding constant of $3.94 \pm(0.15) \times 10^{6}$ and $1.08 \pm(0.10) \times 10^{5} \mathrm{M}^{-1}$. They concluded from electronic absorption spectral changes (hypochromism, redshift and isosbestic points) are indicators of a non-covalent binding mode via intercalation due to strong interactions between chromophore and DNA base pairs [41].

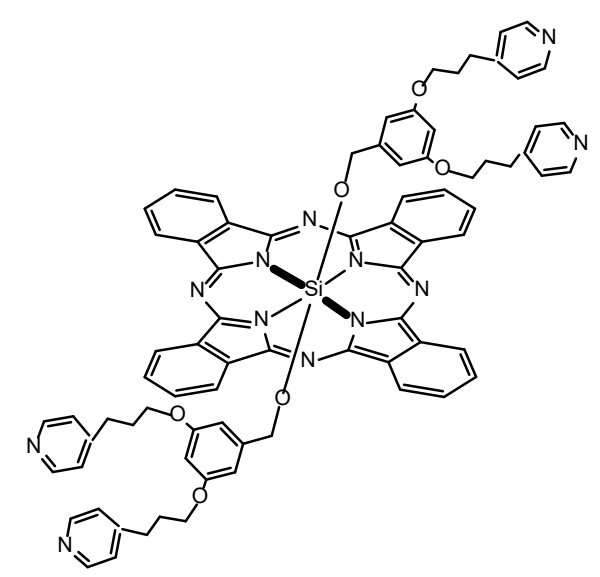

Figure 17. The structure of Si phthalocyanine used in the study of Keleş et al. [41]

Uslan et al., have synthesized new Zinc(II) (5), indium(III) (6), and lutetium(III) (7) phthalocyanines (Pcs) (Fig. 18) peripherally substituted with poly (ethylene glycol) (PEG) monomethyl ether 2000 (PEGME-2000) blocks [42]. The binding constant was calculated from the titration data for 5, 6 and 7 as $9 \times 10^{5}$, $11 \times 10^{5}$, and $10 \times 10^{5}$, respectively. The authors also calculated the thermodynamic parameters and concluded from the results that the binding mode of three phthalocyanines with ct-DNA could be attributed as non-specific, hydrophobic, entropy-controlled, and spontaneous [42].

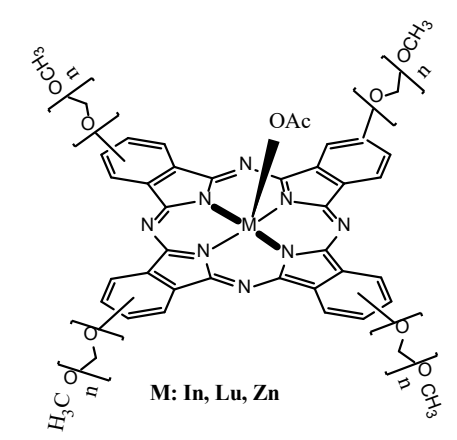

Figure 18. The structure of phthalocyanines used in the study of Uslan et al. [42]

Demirbaş et al., have synthesized triazol compound 3-methyl-4-(3-morpholinopropyl)-1H-1,2,4-triazol5(4H)-one (3), phthalonitrile compound 4-(3-methyl-4(3-morpholinopropyl)-5-oxo-4,5-dihydro-1H-1,2,4triazol-1-yl)phthalonitrile (5), peripherally tetra substituted zinc(II) (6) and copper(II) (7) phthalocyanines and their water-soluble quaternized derivatives (6a) and (7a) (Fig. 19) [43]. The binding constant for ct-DNA interaction was calculated as $6.53 \pm(0.04) \times 10^{4} \mathrm{M}^{-1}$ and $1.14 \pm(0.02) \times 10^{4} \mathrm{M}^{-1}$ for $6 \mathbf{a}$ and 6b. They also found that the $\Delta \mathrm{T}_{\mathrm{m}}$ values as $7.55^{\circ} \mathrm{C}$ and $5.75{ }^{\circ} \mathrm{C}$. The authors concluded that the spectral characteristics, that is observed hypochromicities with redshifts suggest that both compounds interact with ctDNA via intercalation or minor groove binding mode [43].

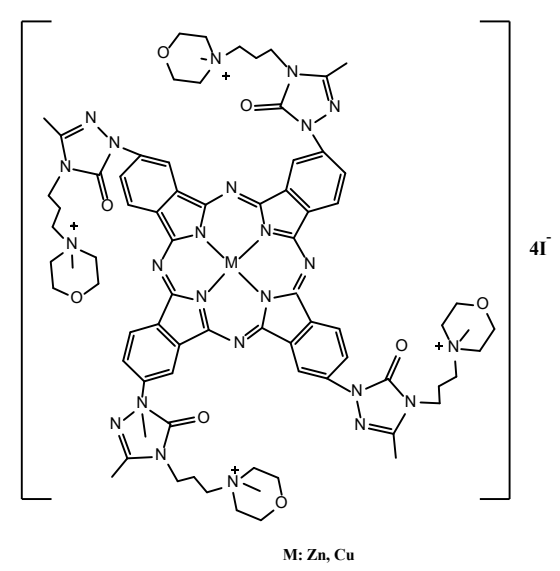

Figure 19. The structure of phthalocyanines used in the study of Demirbaş et al. [43]

Ramos et al., have studied the interaction of four phthalocyanine compounds, with four positive charges and with eight positive charges (ZnPc1 and ZnPc3 contain four positive charges, ZnPc2 and ZnPc4 contain eight positive charges) (Fig. 20) with different DNA structures (tetramolecular G-quadruplex, unimolecular G-quadruplex, salmon sperm DNA, and 5GC small double-strand DNA) [44]. They found that ZnPc1 and ZnPc4 have high selectivity and affinity for Gquadruplex over duplex structures. Ramos et al. have also concluded some important inferences about the structure-activity relationship: They have explained that the existence of a high number of positive charges results in a better affinity but lacks its selectivity towards DNA and the position of the positive charge is important for the interactions; a balance between the number and position of the positive charges, is a fundamental attribute for selectivity of ligands towards G-quadruplex structures [44].

Demirbaş has synthesized peripherally tetra 4-(1phenoxypropan-2-yloxy)-substituted novel zinc(II) phthalocyanine (4) (Fig. 21) [45]. He has found the ctDNA binding constant of compound 4 as $1.73 \pm 0.50 \times 10^{4}$ $\mathrm{M}^{-1}$. A hypochromic effect (27.97\%) after the addition of ct-DNA has been observed. The author also concluded from spectrophotometric titration and ethidium bromide competitive binding experiments that 
phthalocyanine 4 interacted with ct-DNA strongly via non-intercalation mode [45].
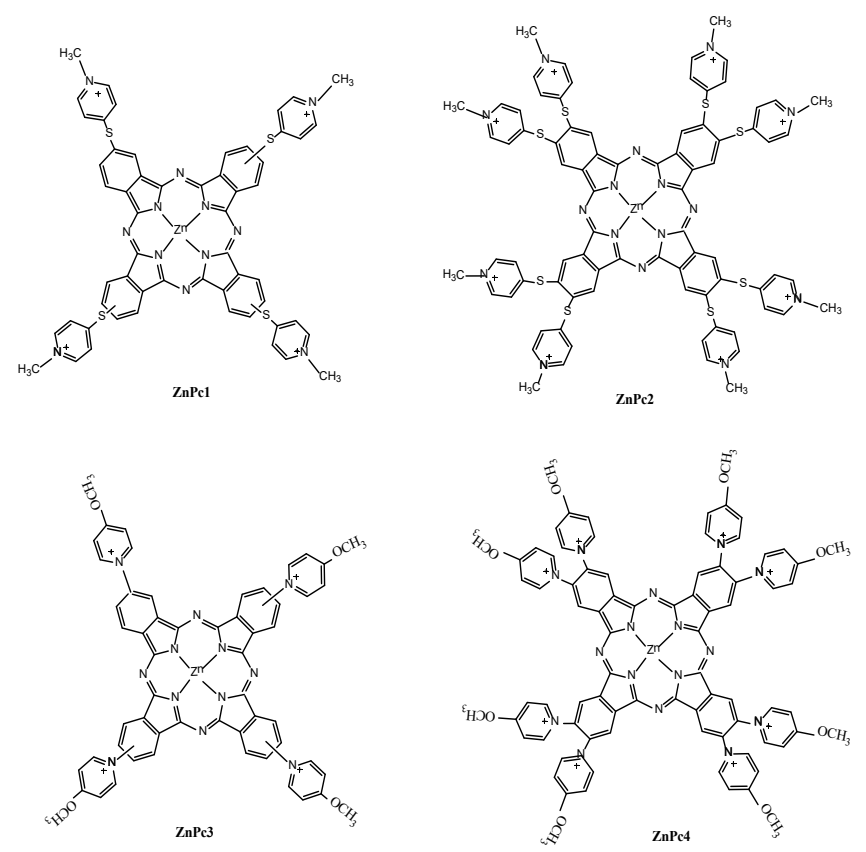

Figure 20. The structure of zinc phthalocyanines used in the study of Ramos et al. [44]

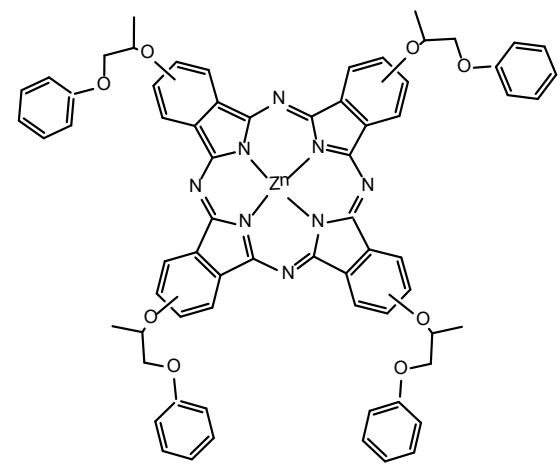

Figure 21. The structure of zinc phthalocyanines used in the study of Demirbaş [45]
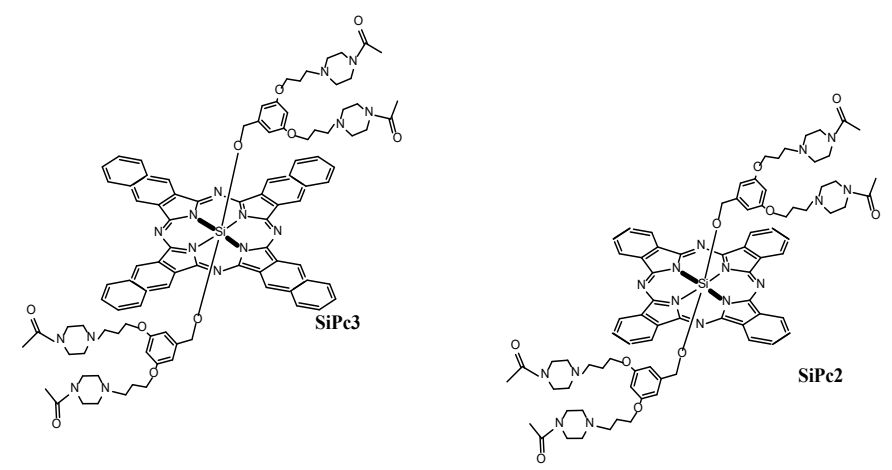

Figure 22. The structure of zinc phthalocyanine used in the study of Baş et al. [46]

Baş et al., have synthesized axially 1-acetylpiperazine substituted silicon (IV) phthalocyanine, naphthalocyanine 2, 3, and their water-soluble derivatives (2a and $\mathbf{2 b}$ ) (Fig. 22) [46]. They studied the ct-
DNA interaction of $\mathbf{2 a}$ and $\mathbf{2} \mathbf{b}$. The binding constans have been calculated as $1.25 \pm(0.01) \times 10^{4}$ and $1.13 \pm$ $(0.03) \times 10^{4} \mathrm{M}^{-1}$. The $50.03 \%$ and $44.98 \%$ hypochromisms and redshifts of $1 \mathrm{~nm}$ and $5 \mathrm{~nm}$ have been observed for the interaction of $\mathbf{2} \mathbf{a}$ and $\mathbf{3 a}$ with DNA. The changes in melting temperatures have been found as $4.25^{\circ} \mathrm{C}$ and $3.75^{\circ} \mathrm{C}$ for $\mathbf{2 a}$ and $\mathbf{3 a}$ [46].

\section{Conclusion}

Investigating the interactions of molecules targeting DNA and G-quadruplex DNA with these structures is very important for drug development studies. Drugs targeting these structures are very important for the treatment of many diseases, including cancer. The ability of phthalocyanines to be synthesized differently to have different properties, to have high absorption in the near IR region, to form species such as singlet oxygen by activating light made these molecules compatible with photodynamic therapy. Until now, important studies have been carried out on this subject and in the light of the obtained data, new compounds more specific to the target will be synthesized.

\section{References}

[1] K. L. M. Santos, R. M. Barros, D. P. da Silva Lima, A. M. A. Nunes, M. R. Sato, R. Faccio, J. A. O. Junior, Prospective application of phthalocyanines in the photodynamic therapy against microorganisms and tumor cells: a mini-review, Photodiagn Photodyn, 2020,102032.

[2] M. Soncin, C. Fabris, A. Busetti, D. Dei, D. Nistri, G. Roncucci, G. Jori, Approaches to selectivity in the $\mathrm{Zn}$ (II)-phthalocyaninephotosensitized inactivation of wild-type and antibiotic-resistant Staphylococcus aureus, Photoch Photobiol Sci, 1(10), 2002, 815819.

[3] B. D. Zheng, Q. X. He, X. Li, J. Yoon, J. D. Huang, Phthalocyanines as contrast agents for photothermal therapy, Coordin Chem Rev, 426, 2021, 213548.

[4] C. P. Ribeiro, L. M. Lourenço, Overview of cationic phthalocyanines for effective photoinactivation of pathogenic microorganisms, J Photoch Photobio C, 2021, 100422.

[5] Z. Dalkılıç, C. B. Lee, H. Choi, I. Nar, N. K. Yavuz, A. K. Burat, Tetra and octa substituted $\mathrm{Zn}$ (II) and $\mathrm{Cu}$ (II) phthalocyanines: Synthesis, characterization and investigation as hole-transporting materials for inverted type-perovskite solar cells, J Organomet Chem, 922, 2020, 121419.

[6] M. V. Martínez-Díaz, M. Ince, T. Torres, Phthalocyanines: colorful macroheterocyclic sensitizers for dye-sensitized solar cells, Monatsh Chem, 142(7), 2011, 699-707.

[7] A. C. Yüzer, G. Kurtay, T. İnce, S. Yurtdaş, E. Harputlu, K. Ocakoglu, M. İnce, Solution-processed small-molecule organic solar cells based on non-aggregated zinc phthalocyanine derivatives: A comparative experimental and theoretical study, Mat Sci Semicon Proc, 129, 2021, 105777.

[8] S. W. Kim, G. Kim, C. S. Moon, T. Y. Yang, J. Seo, Metal-free phthalocyanine as a hole transporting material and a surface passivator for efficient and stable perovskite solar cells, Small Methods, 2021, 2001248.

[9] A. Husain, A. Ganesan, M. Sebastian, S. Makhseed, Large ultrafast nonlinear optical response and excellent optical limiting 
behaviour in pyrene-conjugated zinc (II) phthalocyanines at a near-infrared wavelength, Dyes Pigments, 184, 2021, 108787.

[10] S. I. Qashou, E. F. M. El-Zaidia, A. A. A. Darwish, T. A. Hanafy, Methylsilicon phthalocyanine hydroxide doped PVA films for optoelectronic applications: FTIR spectroscopy, electrical conductivity, linear and nonlinear optical studies, Physica B, 571, 2019, 93-100.

[11] A. Y. Tolbin, M. S. Savelyev, A. Y. Gerasimenko, L. G. Tomilova, N. S. Zefirov, Thermally stable J-type phthalocyanine dimers as new non-linear absorbers for low-threshold optical limiters, Phys Chem Chem Phys, 18(23), 2016, 15964-15971.

[12] I. M. Del Mundo, K. M. Vasquez, G. Wang, Modulation of DNA structure formation using small molecules, Bba-Mol Cell Res, 1866(12), 2019, 118539

[13] A. R. Jalalvand, Chemometrics in investigation of small moleculebiomacromolecule interactions: A review, Int J Biol Macromol, 181, 2021, 478-493.

[14] A. Rescifina, Zagni, C. M. G. Varrica, V. Pistarà, A. Corsaro, Recent advances in small organic molecules as DNA intercalating agents: Synthesis, activity, and modeling, Eur J Med Chem, 74, 2014, 95-115.

[15] A. Awadasseid, X. Ma, Y. Wu, W. Zhang, G-quadruplex stabilization via small-molecules as a potential anti-cancer strategy, Biomed Pharmacother, 139, 2021, 111550.

[16] J. L. Huppert, S. Balasubramanian, Prevalence of quadruplexes in the human genome, Nucleic Acids Res, 33(9), 2005, 2908-2916.

[17] P. A. Summers, B. W. Lewis, J. Gonzalez-Garcia, R. M. Porreca, A. H. Lim, P. Cadinu, R. Vilar, Visualising G-quadruplex DNA dynamics in live cells by fluorescence lifetime imaging microscopy, Nat Commun, 12(1), 2021, 1-11.

[18] M. L. Bochman, K. Paeschke, V. A. Zakian, DNA secondary structures: stability and function of G-quadruplex structures, Nat Rev Genet, 13(11), 2012, 770-780.

[19] S. Neidle, Quadruplex nucleic acids as targets for afnticancer therapeutics, Nat Rev Chem, 1(5), 2017, 1-10.

[20] A. De Magis, S. G. Manzo, M. Russo, J. Marinello, R. Morigi, O. Sordet, G. Capranico, DNA damage and genome instability by Gquadruplex ligands are mediated by $\mathrm{R}$ loops in human cancer cells, Proc Natl Acad Sci, 116(3), 2019, 816-825.

[21] T. Keleş, B. Barut, A. Özel, Z. Biyiklioglu, Design, synthesis and biological evaluation of water soluble and non-aggregated silicon phthalocyanines, naphthalocyanines against A549, SNU-398, SKMEL128, DU-145, BT-20 and HFC cell lines as potential anticancer agents, Bioorg Chem, 107, 2021, 104637.

[22] W. Xiao, X. Guan, B. Huang, T. Q. Ye, Zhang, K. Chen, F. Fu, Fluorinated dendritic silicon (IV) phthalocyanines nanoparticles: Synthesis, photoinduced intramolecular energy transfer and DNA interaction, Dyes Pigments, 186, 2021, 109013.

[23] S. Y. Al-Raqa, K. Khezami, E. N. Kaya, M. Durmuş, A novel water soluble axially substituted silicon (IV) phthalocyanine bearing quaternized 4-(4-pyridinyl) phenol groups: synthesis, characterization, photophysicochemical properties and BSA/DNA binding behavior, Polyhedron, 194, 2021, 114937.

[24] E. Bağda, E. Bağda, A. Kocak, M. Durmuş, Investigation of Binding behaviour of a water-soluble gallium (III) phthalocyanine with double-stranded and G-quadruplex DNA via experimental and computational methods, J Mol Struct, 1240, 2021, 130536.

[25] M. Uchiyama, A. Momotake, T. Ikeue, Y. Yamamoto, Stepwise binding of a cationic phthalocyanine derivative to an all parallelstranded tetrameric G-quadruplex DNA, J Inorg Biochem, 213, 2020, 111270 .

[26] F. Macii, C. Perez-Arnaiz, L. Arrico, N. Busto, B. Garcia, T. Biver, Alcian blue pyridine variant interaction with DNA and RNA polynucleotides and G-quadruplexes: changes in the binding features for different biosubstrates, J Inorg Biochem, 212, 2020, 111199.
[27] G. S. Amitha, S. Vasudevan, DNA binding and cleavage studies of novel Betti base substituted quaternary $\mathrm{Cu}$ (II) and $\mathrm{Zn}$ (II) phthalocyanines, Polyhedron, 190, 2020, 114773.

[28] Ö. Çoban, B. Barut, C. Ö. Yalçın, A. Özel, Z. Bıyıklığlu, Development and in vitro evaluation of BSA-coated liposomes containing Zn (II) phthalocyanine-containing ferrocene groups for photodynamic therapy of lung cancer, J Organomet Chem, 925, 2020, 121469.

[29] B. Barut, C. Ö. Yalçın, Ü. Demirbaş, H. T. Akçay, H. Kantekin, A. Özel, The novel Zn (II) phthalocyanines: Synthesis, characterization, photochemical, DNA interaction and cytotoxic/phototoxic properties, J Mol Struct, 1218, 2020, 128502.

[30] K. Khezami, K. Harmandar, E. Bağda, E. Bağda, G. Şahin, N. Karakodak, M. Durmuş, The new water soluble zinc (II) phthalocyanines substituted with morpholine groups-synthesis and optical properties, J Photoch Photobio A, 401, 2020, 112736.

[31] J. Lopes-Nunes, J. Carvalho, J. Figueiredo, C. I. Ramos, L. M. Lourenço, J. P. Tomé, C. Cruz, Phthalocyanines for G-quadruplex aptamers binding, Bioorg Chem, 100, 2020, 103920.

[32] Z. Ballı, A. Arslantaş, D. G. Solğun, M. S. Ağırtaş, DNA binding studies of the 2,10,16, 24-tetrakis (phenoxy-3-methoxybenzoic acid) phthalocyaninato) $\mathrm{Co}$ (II) and $\mathrm{Cu}$ (II) compounds, SN Appl Sciences, 2(5), 2020, 1-10.

[33] M. Uchiyama, A. Momotake, N. Kobayashi, Y. Yamamoto, Specific binding of an anionic phthalocyanine derivative to Gquadruplex DNAs, Chem Lett, 49(5), 2020, 530-533.

[34] H. Yalazan, B. Barut, B. Ertem, C. Ö. Yalçın, Y. Ünver, A. Özel, H. Kantekin, DNA interaction and anticancer properties of new peripheral phthalocyanines carrying tosylated 4morpholinoaniline units, Polyhedron, 177, 2020, 114319.

[35] S. Yan, H. Guo, J. Su, J. Chen, X. Song, M. Huang, Z. Chen, Effects of hydroxyl radicals produced by a zinc phthalocyanine photosensitizer on tumor DNA, Dyes Pigments, 173, 2020, 107894.

[36] Z. Wang, J. Li, J. Liu, L. Wang, Y. Lu, J. P. Liu, Molecular insight into the selective binding between human telomere G-quadruplex and a negatively charged stabilizer, Clin Exp Pharmacol P, 47(5), 2020, 892-902.

[37] G. S. Amitha, S. Vasudevan, DNA/BSA binding studies of peripherally tetra substituted neutral azophenoxy zinc phthalocyanine, Polyhedron, 175, 2020, 114208.

[38] A. Baran, S. Col, E. Karakılıç, F. Özen, Photophysical, photochemical and DNA binding studies of prepared phthalocyanines, Polyhedron, 175, 2020, 114205.

[39] N. A. Kasyanenko, R. A. Tikhomirov, V. M. Bakulev, V. N. Demidov, E. V. Chikhirzhina, E. B. Moroshkina, DNA complexes with cobalt (II) phthalocyanine disodium disulfonate, ACS Omega, 4(16), 2019. 16935-16942.

[40] E. K. McRae, D. E. Nevonen, S. A. McKenna, V. N. Nemykin, Binding and photodynamic action of the cationic zinc phthalocyanines with different types of DNA toward understanding of their cancer therapy activity, J Inorg Biochem, 199, 2019, 110793.

[41] T. Keleş, B. Barut, A. Özel, Z. Biyiklioglu, Synthesis of water soluble silicon phthacyanine, naphthalocyanine bearing pyridine groups and investigation of their DNA interaction, topoisomerase inhibition, cytotoxic effects and cell cycle arrest properties, Dyes Pigments, 164, 2019, 372-383.

[42] C. Uslan, B. Köksoy, M. Durmuş, N. D. İşleyen, Y. Öztürk, Z. P. Çakar, B. S. Sesalan, The synthesis and investigation of photochemical, photophysical and biological properties of new lutetium, indium, and zinc phthalocyanines substituted with PEGME-2000 blocks, J Biol Inorg Chem, 24(2), 2019, 191-210.

[43] Ü. Demirbaş, B. Barut, A. Özel, F. Çelik, H. Kantekin, K. Sancak, Synthesis, characterization and DNA interaction properties of the novel peripherally tetra 4-(3-methyl-4-(3-morpholinopropyl)-5oxo-4, 5-dihydro-1H-1, 2, 4-triazol-1-yl) substituted water soluble Zn (II) and Cu (II) phthalocyanines, J Mol Struct, 1177, 2019, 571578 . 
[44] C. I. V. Ramos, S. P. Almeida, L. M. Lourenço, P. M. Pereira, R. Fernandes, M. A. F. Faustino, M. G. P. M. S. Neves, Multicharged phthalocyanines as selective ligands for G-quadruplex DNA structures, Molecules, 24(4), 2019, 733.

[45] Ü. Demirbaş, Synthesis, characterization, and investigation of singlet oxygen, DNA interaction, and topoisomerase I inhibition properties of novel zinc (II) phthalocyanine, Turk J Chem, 43(6), 2019, 1646-1655.

[46] H. Baş, B. Barut, Z. Biyiklioglu, A. Özel, Synthesis, DNA interaction, topoisomerase I, II inhibitory and cytotoxic effects of water soluble silicon (IV) phthalocyanine and napthalocyanines bearing 1-acetylpiperazine units, Dyes Pigments, 160, 2019, 136144 . 